$\begin{gathered}\text { EPiC Series in Built Environment } \\ \text { Volume 2, 2021, Pages 568-577 } \\ \text { ASC 2021. 57th Annual Associated Schools } \\ \text { of Construction International Conference }\end{gathered}$
Built
Environment

\title{
Student Responses to Faculty Innovation in Virtual Construction Education
}

\author{
Kieren H. McCord and Steven K. Ayer, Ph.D. \\ Arizona State University \\ Tempe, AZ
}

In response to the global coronavirus pandemic, much of higher education experienced a shift to virtual teaching and learning, requiring instructors to swiftly adapt their teaching methods. Within a construction education context, faculty interviews were conducted to discover some of the innovations and teaching strategies that were implemented. Using this data, a questionnaire was developed and delivered to students, who indicated their perceptions of these strategies and noted what they found to be helpful and what they found to be counterproductive. In general, students responded well to innovations such as virtual interactive elements and providing recorded lectures for review. Many students expressed frustration with slide-based lecturing and a loss of hands-on opportunities, a particularly poignant concern in construction education. Many teaching strategies had mixed reception, sometimes depending on the effectiveness of application. Organization and communicating expectations were emphasized by more than half of the students. In addition to discussing general strategies, anecdotal evidence is provided for construction-specific student experiences that were either successful or challenging. The contribution of this work is in providing a timely survey of construction-specific teaching strategies from faculty who experienced the transition to virtual and in directly collecting student responses to these strategies.

Key Words: virtual education, remote education, construction education, COVID response

\section{Introduction}

The coronavirus pandemic in 2020 has led to substantial shifts in the delivery of higher education. There is not yet widespread agreement about what methods are most effective. While the pandemic catalyzed the immediate need for changing educational strategies, prior researchers were already arguing that construction education needed to evolve. For example, traditional lecture-based content delivery has been critiqued for being ineffective and has led researchers to call for a re-evaluation of construction education delivery (Reyes \& Gálvez, 2011). As we continue to evolve in construction education, we have an opportunity to learn the ways in which new modes of education do and do not work by studying the rapid changes that have taken place due to COVID.

To understand the challenges specific to construction education delivery in a virtual context, a series of interviews were conducted with a sample of construction faculty. To gain insight from the student 
side, several students were provided with questionnaires and asked to explain their perspective regarding the shift to virtual education. They explained which teaching techniques they felt contributed to their learning and which may be less effective. They were also asked to provide insights into any innovative strategies they would like to see applied in the classroom. The research questions addressed in this paper include:

- What teaching strategies were implemented by construction and civil engineering faculty in response to the pandemic and subsequent shift to virtual learning?

- How did students respond to these teaching strategies?

The faculty members who participated in the interviews discussed strategies that can apply across disciplines as well as strategies specific only to construction education. Both types of result are presented to best represent the opinions of construction faculty and responses of construction students in all aspects.

Recent literature has explored effective techniques in the related discipline of civil engineering, including techniques that encourage student participation and classroom control (Forcael et al., 2019) or that look at strategies for teaching specific topics such as structural analysis (Aparicio \& RuizTeran, 2007). Within the construction discipline, there has been both past and recent research on strategies for teaching specific construction skills, such as BIM (Wang \& Leite, 2014) or project management (Abudayyeh \& Andersen, 1999). However, there is a lack of research regarding teaching techniques for delivering a holistic construction education in a virtual format. The contribution of this work is in exploring remote or virtual construction education strategies by directly surveying both faculty and students who have experienced both in-person and virtual construction teaching and learning.

\section{Methods}

Both faculty and students were asked to provide their perspective on delivery methods for virtual construction education. Five faculty members were interviewed and 12 students were surveyed for this work.

For the faculty perspectives, a sample of civil and construction engineering and management faculty members was identified whose courses shifted to being taught remotely after March of 2020 when the coronavirus pandemic necessitated remote education. Faculty members were selected to include instructors from a variety of subjects within the discipline, including mechanical systems, leadership in project management, construction technology, strength of materials, and construction drawings/graphics. The selected faculty were also chosen to represent a variety of teaching experience levels, from 1 to 25 years and including adjunct, associate, and tenured professors. Additionally, two of the interviewees were full-time industry practitioners who taught part-time. All instructors taught at least some components of their class in a synchronous virtual format. The selected individuals were invited to participate in semi-structured interviews to report their perceptions about this shift in educational modes. This format has been used in educational research to balance pre-preparation of questions with the ability to adapt to organically emerging topics and questions (Szombatová, 2016). Semi-structured interviews allow flexibility for the interviewees to ideate on unexpected or new topics. The interviewees were asked to discuss their typical class format before the shift to virtual, and then describe the changes they underwent in the transition. They were asked to reflect particularly on challenges they encountered and strategies they used to overcome these challenges. These interviews 
were recorded and analyzed thematically. Specifically, teaching strategies that were mentioned by at least once in the interviews were noted and those with different wording, but similar content, were consolidated. For example, references to "slide presentations" and "PowerPoint" would be considered the same strategy. In addition to written notes during the actual interview, the video recordings of the interviews were each reviewed by a member of the research team to gather this information.

After interviewing faculty members and analyzing the strategies, their responses were directly used to formulate a questionnaire to understand the student response to these techniques. If a technique or strategy was mentioned by one or multiple faculty members, it was included on the survey. The strategies that emerged are shown in the results section in Figures 1 and 2. The researchers identified a sample of construction management students who experienced a shift from primarily in-person to primarily remote education. The students from a course cross-listed on both the construction management and construction engineering major map and a parallel graduate course were invited to take the survey. These students were asked to indicate their perceptions about these topics in a multiple-choice format and were also given the opportunity to voice opinions in open-ended questions. For the multiple-choice questions, students indicated whether or not they had experienced a particular strategy (yes/no). Students also considered the strategies and rated their effectiveness on a 1-5 Likert scale of effectiveness. For the open-ended portion, students were asked to describe challenges they faced in the virtual learning environment as well as strategies they have seen used in the classroom that facilitated their learning in an open-ended format. They were asked to ideate regarding any strategies they would like to see implemented in the classroom that may facilitate better learning.

First, the student responses to the faculty strategies were analyzed using the simple mean and visual representations of spread. Following this analysis, the student open-ended responses were thematically analyzed and common comments and concerns were extracted and are presented in aggregate form with specific anecdotal examples. First, a discussion of the student responses to the teaching strategies is presented, followed by a thematic analysis of the students' open-ended responses first regarding general techniques then regarding construction-discipline-specific techniques. The following analysis is exploratory and not intended as a conclusive representation of all construction students.

\section{Results and Discussion}

\section{Student Responses to Faculty Strategies}

The virtual teaching strategies that construction educators indicated using or considering for use in their classrooms included lecturing with slides or a visual presentation, lecturing with only their video on, having guest lecturers deliver content, using breakout rooms, providing remote labs, utilizing virtual interactive content such as digital whiteboards or screen annotation, group games, role play, and virtual site visits. The sample of student respondents was comprised of 58\% Undergraduate Seniors, 17\% Undergraduate Juniors, and 25\% Graduate Students. The number of students within the sample who experienced these techniques is found in Figure 1. This figure illustrates which techniques are most commonly used in the classroom - various lecturing techniques, breakout rooms, and virtual interactive elements - and which are less common — group games, role play, and virtual site visits. 


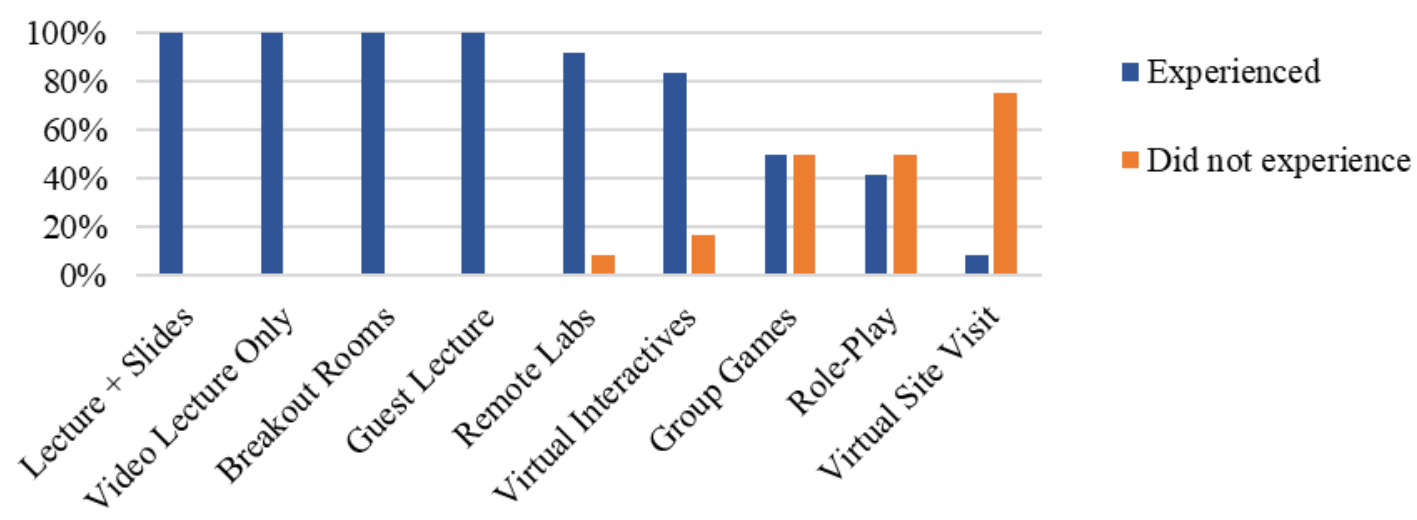

Figure 1. Number of students who experienced each of the teaching techniques mentioned by faculty. $(n=12)$

Student reception of a teaching technique represents one component of effectiveness and was measured for each of these strategies. On the survey, students indicated how effective they perceived a technique to be on a Likert scale from 1 (Not at all effective) to 5 (Extremely effective). The results of the survey are presented in Figure 2. In this figure, the grey dots represent the individual student responses (larger dots represent more students choosing that rating) and the blue dots represent the average (larger dots represent more student ratings). Students did not have to experience the technique to indicate their reception of the concept, such as the student who indicated they think a site visit would be moderately effective but hadn't yet experienced one. Many of the techniques received mixed reviews, such as video lecture only, with some students rating it at a 1 and others at a 5, with the average sitting just below 3 . Others were rated much lower, like virtual labs, which had an average rating of 1.8. The highest rated technique was guest lecturers, which was rated at 3.5 and there were no techniques that received above a 4-point average, showing mixed feelings toward most techniques. This format selected for Figure 2 represents not only averages, but also the spread of each individual data point since the sample was comparatively small. Such a large spread even with a small sample size shows the variety of opinions and lack of convergence regarding virtual education strategies. 


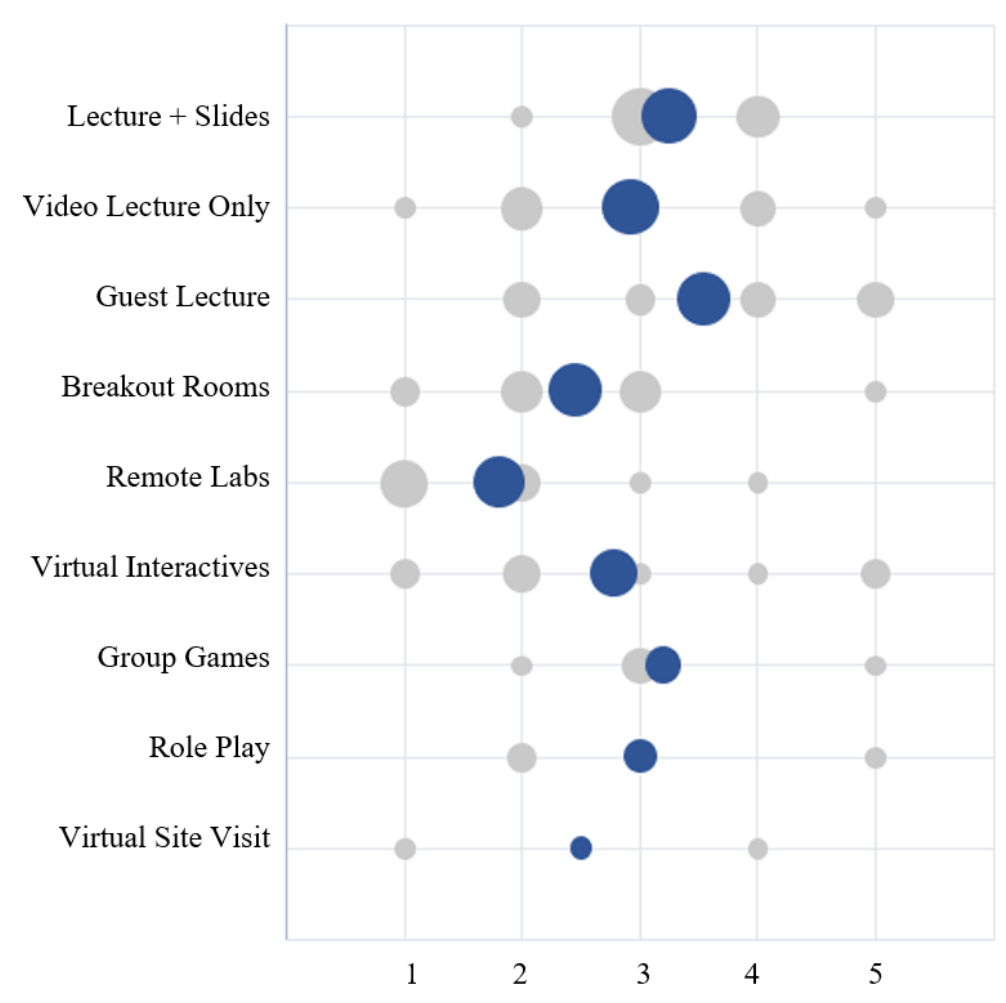

Figure 2. Student perceptions of effectiveness of specific teaching strategies on a scale from 1 (Not at all effective) to 5 (Extremely effective), organized from top to bottom by number of responses. $(\mathrm{n}=12)$.

\section{General Strategies}

This spread of opinions not only emerged in the multiple-choice results but also in the open-ended responses. Students were asked to write about the most effective and the least effective strategies that their professors in the construction domain had implemented to enhance virtual learning. In these responses, students could discuss techniques that were previously mentioned in the multiple-choice portion or any other strategies they had seen in the classroom. The open-ended responses from students were analyzed thematically to see which elements of virtual construction education received general negative, positive, or mixed reception. Table 1 shows the concepts and teaching strategies that fell in each of these categories and a brief discussion of each column follows. In this context, negative agreement refers to concepts that most participants agreed did not work or had a negative impact on learning. Positive agreement refers to concepts that most participants agreed had a positive impact on their virtual learning experience, and conflicting opinions refers to concepts where most participants held diverging viewpoints. 
Table 1

Virtual construction education themes from student open-ended responses with general negative agreement, general positive agreement, and conflicting opinions.

\begin{tabular}{lll}
\hline Negative Agreement & Conflicting Opinions & Positive Agreement \\
\hline $\begin{array}{l}\text { No change from in-person } \\
\text { strategies and expectations) }\end{array}$ & $\begin{array}{l}\text { Increasing amount of content } \\
\text { and resources }\end{array}$ & Innovative classroom activities \\
Lecture Only & Watch-ahead lectures & Recorded lectures for review \\
$\begin{array}{l}\text { Relying only on slide } \\
\text { presentations }\end{array}$ & Group projects & Industry guest lecturers \\
$\begin{array}{l}\text { Loss of in-field or hands-on } \\
\text { opportunities or training }\end{array}$ & Breakout rooms & Consistent communication \\
\hline
\end{tabular}

\section{Negative Agreement}

In the category of negative agreement, students did not respond well to classes that only had lectures or that only relied on slide presentations and did not explore alternative teaching approaches. Finally, students expressed frustration with the lack of in-field opportunities or training, with some students having hands-on opportunities scheduled that ultimately did not happen due to the pandemic. While these responses may not be surprising, the ubiquity of these frustrations and the call from students for innovation can guide instructors who may be hesitant to try new techniques. Traditional resistance that students may have to classroom changes (Keeney-Kennicutt \& Gunersel, 2008) may be overcome by the shared experience of both student and teacher facing uncontrollable changes.

\section{Positive Agreement}

Most students expressed positive reception to guest lecturers from industry, stating that they helped "stimulate the brain". It should be noted as well that faculty interviewees also mentioned guest lecturers in a positive light. Next, while most students did not prefer lecture-based learning alone, they generally appreciated having the lectures available after class for review. Additionally, clear organization and consistent communication was noted and appreciated by students. While this is always important, consistent and frequent communication is even more crucial in a virtual format where there is no true face to face contact. The majority of students (58\%) mentioned organization, communication, or some sort of confusion or disconnect in expectations between the professors and the students. The frequency of this comment may indicate that faculty members may need to take additional care in the virtual format to ensure that what they think is clear truly comes across to students as intended.

\section{Mixed Responses}

While there were some areas with general negative and general positive agreement, many strategies had mixed reactions from students. Some students appreciated more content and supplementary resources, such as class podcasts or "exercises based on external links". However, others felt that too many resources and content were thrown at them and they felt overwhelmed. These mixed feelings 
apply to watch-ahead lectures as well, with some students appreciating the ability to work ahead, with others expressing frustration that they were expected to learn and retain information prior to class and would prefer to have it taught to them in real time. Recall that there was general positive agreement about posting lectures following class, so the recorded lecture strategy may be effective, but is much better received after content has been presented in real time. Group projects received mixed reviews as well from the construction students. Some students thought that working in groups helped motivate them and keep them accountable, while others felt that coordinating with others while not being able to meet in-person presented unduly difficult challenges, such as coordinating over vastly disparate time zones. Similar to group work outside of class, group work during class also had mixed reception, with some students mentioning how breakout rooms were effective in helping them solidify concepts taught in the main lecture, especially when there were sufficient TAs to come into the rooms and answer questions. Others stated that breakout rooms were too "awkward" or that there was "no accountability" for what happened in the rooms. If instructors use breakout rooms, it is suggested that they set clear objectives and have a plan to retain interaction with the students during that time.

The final strategy with mixed results was having videos on. In truth, most students who mentioned this strategy were not in favor and suggested that many students have circumstances where they are not comfortable sharing video. It is included in the conflicting opinions section, however, because instructors listed it as very helpful, suggesting that when students had their videos on, the instructors could gauge student reactions and comprehension and connect better with them. The instructors did, however, acknowledge potential logistical or ethical concerns with forcing students to turn on their video cameras. This will likely be a persistent topic in virtual education and even simple techniques like encouraging virtual backgrounds could help students feel comfortable if privacy is a concern.

Overall, the emergent themes from the open-ended questions regarding construction education delivery strategies illustrate that there are such various preferences by faculty and students that it may be best to try to diversify in the modes of education that are employed in the construction classroom. The faculty interviews took place during the early months of the pandemic and the student survey was conducted later in the year (during the Fall 2020 semester), so there is an adjustment period that could influence these results.

\section{Construction-Specific Strategies and Examples}

The results presented in the previous section, while representing the opinions of construction-specific faculty and students, discussed a variety of teaching strategies and techniques that can be found in most virtual classrooms regardless of subject matter. While the aforementioned themes and techniques still have relevance to the construction classroom and reflect the views of this sample of construction students and faculty, this section dives into a few emergent themes that relate more specifically to the unique needs of a construction classroom. In particular, classroom interaction techniques, virtual labs, and virtual site visits will be discussed.

First, some students noted classroom techniques that were particularly impactful for their construction related courses, especially those that involved complex construction concepts or computation, including effective use of virtual whiteboards and recording step-by-step processes. For example, one student related an experience where their instructor attempted to use the virtual whiteboard to walk students through complex math problems involving structural analysis, but it was difficult with a typical mouse and trackpad. They tried simply showing snapshots of the solution key, but this was not effective either. After experiencing these difficulties and considering other solutions, the instructor 
found that connecting to the virtual meeting through a tablet that had a pencil allowed them to easily and effectively illustrate these complex topics in a free-handed way that allowed for adjustment to student questions and helped the students follow the process. Another example experience is where a student noted that they had difficulty understanding the quantity take-off process during lecture, but because the instructor posted the video recording of the process, the student was able to review and complete the quantity take-off assignment on their own.

In addition to the typical classroom experiences, many construction programs provide lab experiences to help their students gain hands-on experience with software they may use after entering the industry, such as design, planning, or scheduling software. Many universities already provide these computer labs in a virtual format, enabling students to connect from home. Recall, however, the poor reception to this "Remote Labs" strategy in Figure 2. While a complete rationale for this low rating was not provided in the responses, many students did experience technical difficulties when accessing these labs, which likely led to frustration regarding the strategy, which should ideally be an enjoyable, hands-on experience. It is suggested that educators streamline the process to access these virtual labs, ensuring that the challenges students face are in learning concepts and skills within the software, not in simply accessing software, which may be a more common issue than current faculty realize.

In addition to classroom and lab experiences, the out-of-class experience is just as crucial to construction education, if not more so. While only one student surveyed had experienced a virtual site visit, several faculty interviewees mentioned concern regarding the inability to access construction sites for students. Recently, educators have been realizing more and more the importance of site visits (Eiris Pereira \& Gheisari, 2019; Murray \& Tennant, 2016). The link between industry and the classroom is crucial in civil and construction education. Site visits provide students with valuable understanding of construction means and methods and, according to one interviewee, valuable inperson interaction with project personnel and clients. Several interviewees recognized the importance of interacting with those currently practicing in the industry. Additionally, on-site internships teach students valuable hands-on skills such as trade knowledge or software skills. Overall, results from both faculty and students mentioned the challenges associated with delivering experiences outside the traditional classroom setting, highlighting the need for innovation in this area.

While there is not one simple solution to providing these experiences to students, several interviewees pointed out the potential of virtual site visits via video or immersive virtual reality, an innovation that has been ongoing for decades but has become even more valuable at this time (Kumaraswamy, 2004; Jaselskis et al., 2010; Ashford \& Mills, 2006). One interviewee discussed how their university already had an ongoing project developing a virtual construction site visit to implement in the classroom. Overall, virtual site visits and other virtual hands-on experiences provide a promising alternative to conventional visits when those are not possible. Basic video viewing technology is available to nearly all university students, and even virtual reality applications are becoming more accessible through emulators, affordable at-home setups, or even adapted to simple 360-degree video-viewing formats (Pham et al., 2018).

Even when COVID restrictions are over, these methods can augment classroom instruction in an even more accessible way, especially when class size or proximity of construction sites makes site visits difficult. For example, virtual site visits can allow rural students to experience urban construction without extensive travel and vice-versa. Even further, students can more easily become global citizens by virtually experiencing the built environment in locations and countries that may not be accessible to them otherwise. Students can also visit sites in a safe manner that could be unsafe in person or only accessible to people with extensive training. These experiences are not yet ubiquitous, but with the 
rapid development of technology, they soon can be, and they show great learning potential based on past research (Eiris Pereira \& Gheisari, 2019).

\section{Conclusion}

COVID has been a catalyst for unprecedented change in construction education, providing educators the opportunity to evaluate what has and has not worked for construction education. This paper presents some preliminary work on student responses to faculty techniques in response to the shift to virtual learning. While virtual may not be the only option going forward, it will likely play a permanent role in higher education, so educators should be intentional about which changes they decide to pursue in the classroom, in labs, and for in-field experiences. For example, students appreciate virtual interactive techniques in favor of only using slide or video lectures. Virtual labs present an opportunity for hands-on experience, especially if particular care is taken to guide students through potential technological barriers. Finally, alternate approaches to providing in-field experiences can be explored. For example, future work from the authors will explore the use of immersive AR technology to enable students to participate in construction scenarios in a socially distant and physically safe environment. Virtual site visits are also an accessible format that can bring some benefits of on-site visits to the virtual classroom. Overall, this study provides insights into potential strategies for remote instruction in a construction education context. Future work can ask similar questions to a larger sample and after more time has passed in order to see if some of the diverse opinions begin to converge over time. This topic will benefit from continued research as the virtual education scene continues to evolve and grow.

\section{References}

Abudayyeh, O., \& Andersen, K. (1999). Integrated construction project management: a teaching case study. Journal of Professional Issues in Engineering Education and Practice, 125(4), 133137.

Aparicio, A. C., \& Ruiz-Teran, A. M. (2007). Tradition and innovation in teaching structural design in civil engineering. Journal of Professional Issues in Engineering Education and Practice, 133(4), 340-349.

Ashford, P., \& Mills, A. (2006, January). Evaluating the effectiveness of construction site visits as a learning experience for undergraduate students enrolled in a built environment course. In $T L$ Forum 2006: Experience of Learning: Proceedings of the 15th Annual Teaching Learning Forum. The University of Western Australia.

Eiris Pereira, R., \& Gheisari, M. (2019). Site visit application in construction education: a descriptive study of faculty members. International Journal of Construction Education and Research, 15(2), 83-99.

Forcael, E., Garcés, G., Bastías, E., \& Friz, M. (2019). Theory of teaching techniques used in civil engineering programs. Journal of Professional Issues in Engineering Education and Practice, 145(2), 02518008.

Jaselskis, E. J., Jahren, C. T., Jewell, P. G., Floyd, E., \& Becker, T. C. (2010). Virtual construction project field trips using remote classroom technology. In Construction Research Congress 2010: Innovation for Reshaping Construction Practice (pp. 236-245).

Keeney-Kennicutt, W., \& Gunersel, B. (2008). Overcoming student resistance to a teaching innovation. International Journal for the Scholarship of Teaching and Learning, 2(1), n1. 
Kumaraswamy, M. M. (2004). Accelerating learning via virtual site visits. International Journal of IT in Architecture Engineering and Construction, 2, 19-32.

Murray, M., \& Tennant, S. (2016, July). " Off-piste pedagogy": construction site visits for undergraduate civil engineers. In Sixth International Symposium of Engineering Education (pp. 165-172).

Pham, H. C., Dao, N., Pedro, A., Le, Q. T., Hussain, R., Cho, S., \& Park, C. S. I. K. (2018). Virtual field trip for mobile construction safety education using 360-degree panoramic virtual reality. Int. J. Eng. Educ, 34(4), 1174-1191.

Reyes, E., \& Gálvez, J. C. (2011). Introduction of innovations into the traditional teaching of construction and building materials. Journal of Professional Issues in Engineering Education and Practice, 137(1), 28-37.

Szombatová, V. (2016). The semi-structured interview in foreign language education research. In The International Conference on Language and Literature in Education and Research 2016.

Wang, L., \& Leite, F. (2014). Process-oriented approach of teaching building information modeling in construction management. Journal of professional issues in engineering education and practice, 140(4), 04014004. 